\title{
Anxiety, normative uncertainty, and social regulation
}

\section{Charlie Kurth}

\section{Biology \& Philosophy}

ISSN 0169-3867

Volume 31

Number 1

Biol Philos (2016) 31:1-21

DOI 10.1007/s10539-015-9508-9
Volume 31 - Number 1 - January 2016

\section{BIOLOGY \& PHILOSOPHY}

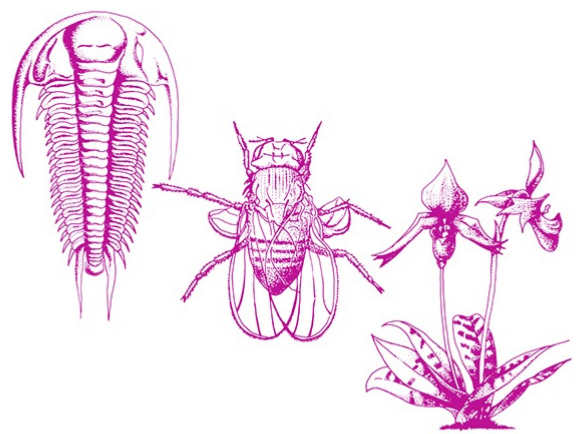

Springer

包 Springer 
Your article is protected by copyright and all rights are held exclusively by Springer Science +Business Media Dordrecht. This e-offprint is for personal use only and shall not be selfarchived in electronic repositories. If you wish to self-archive your article, please use the accepted manuscript version for posting on your own website. You may further deposit the accepted manuscript version in any repository, provided it is only made publicly available 12 months after official publication or later and provided acknowledgement is given to the original source of publication and a link is inserted to the published article on Springer's website. The link must be accompanied by the following text: "The final publication is available at link.springer.com". 


\title{
Anxiety, normative uncertainty, and social regulation
}

\author{
Charlie Kurth ${ }^{1}$
}

Received: 7 May 2015/Accepted: 31 October 2015/Published online: 12 November 2015

(C) Springer Science+Business Media Dordrecht 2015

\begin{abstract}
Emotion plays an important role in securing social stability. But while emotions like fear, anger, and guilt have received much attention in this context, little work has been done to understand the role that anxiety plays. That's unfortunate. I argue that a particular form of anxiety-what I call 'practical anxiety' plays an important, but as of yet unrecognized, role in norm-based social regulation. More specifically, it provides a valuable form of metacognition, one that contributes to social stability by helping individuals negotiate the challenges that come from having to act in the face of unclear norms.
\end{abstract}

Keywords Emotion · Anxiety · Fear - Social regulation - Cooperation · Uncertainty

Cooperation, especially complex cooperation, is greatly facilitated by the presence of stable social structures. Individuals, for instance, need to be able to coordinate expectations; they also need to be able to rely on alliances and divisions of labor. But recognizing this prompts questions. After all, stable social organization doesn't just appear. It must be cultivated and policed. Moreover, the underlying capacities and dispositions that help make complex cooperation possible are things that have been shaped (in part) by evolutionary forces (Sterelny et al. 2013). So how can we explain all this? Emotions are generally thought to be an important part of the answer-they are tools that help build and maintain the stability that makes complex cooperation possible. Examples are easy to come by: fear prompts restraint, anger makes individuals more willing to punish, guilt fosters reparatory behavior. But while emotions like fear, anger, and guilt have received much attention in this context (e.g., Darwin 1873; Ekman 1992; Lazarus 1991; Frank

Charlie Kurth

ckurth@wustl.edu

1 Washington University in Saint Louis, St Louis, MO, USA 
1988; Gibbard 1990; Prinz 2007), very little work has been done to understand the role of anxiety. ${ }^{1}$ That's unfortunate: anxiety plays a central part in explaining how individuals and groups manage to secure the stability that allows for complex cooperative activity.

To demonstrate this, I defend three theses. First, I argue that anxiety evolved alongside fear in order to help address the challenges that come with increasingly sophisticated, norm-based forms of social organization: as social life became more complicated, so did the associated forms of fear and anxiety. Second, I show that a particular form of anxiety — what I call 'practical anxiety' — plays a crucial, but as of yet unrecognized, role in norm-based social regulation. Third, I argue that practical anxiety is able to play this regulative role because it engages distinctive cognitive and motivational capacities - capacities allow practical anxiety to shape decision making in ways that are generally for the better. The result is significant: an account that shows practical anxiety to be a valuable form of metacognition, one that helps secure the social stability and accord that makes complex cooperation possible.

\section{Fear and anxiety: from defensive mechanisms to tools of social regulation}

The argument for my first thesis - namely, that anxiety developed alongside fear in order to help address the complexities of social life-starts with a question. Work on the evolutionary foundations of fear and anxiety indicates that these emotions originated as responses to predators, cliff edges, and other environmental dangers (Öhman 1986, 2008). But if that's right, then how could these responses to environmental threats be used as tools for social regulation? The short answer is that they became more sophisticated. As we will see, looking to the role that fear and anxiety play in regulating increasingly complex forms of social organization (e.g., dominance hierarchies, norm-and-punishment based systems) reveals that there's an important, symbiotic relationship between these emotions and complex forms of social organization: more complex forms of social life co-evolved with more complex emotional capacities. ${ }^{2}$

Since the account of fear's role in this process is more familiar, I will begin here, looking in particular at fear's contribution to the development of the complex social structures that we find in primate groups and hominin/human societies. Doing this will reveal that anxiety also evolved to play a crucial role in promoting these social structures. Moreover, we will also see both that these emotions bring benefits to both individuals (e.g., avoiding punishment) and groups (e.g., increased stability

\footnotetext{
1 But see Baumeister and Tice (1990), Marks and Nesse (1994).

2 Two points. First, on terminology: 'anxiety', as used in ordinary speech, philosophy, and psychology, refers to a range of phenomena that are unlikely to constitute a unified kind. So I will follow others in using the term to focus on varieties of anxiety concerned with uncertain threats and dangers. Second, because we do not have a settled account of what emotions are, I aim to be (largely) neutral regarding these debates.
} 
and cooperation), and that the benefits to groups become more pronounced as social life becomes more complex. ${ }^{3}$ With this initial picture of fear and anxiety in hand, we will be positioned to raise further questions about the extent to which fear and anxiety - at least as standardly understood - are able to explain how social stability and cooperation remained possible as hominin/human social life became more complicated. Addressing this issue will be the focus of the rest of the paper.

\section{Evolutionary foundations: fear and anxiety}

To understand how fear and anxiety developed into sophisticated mechanisms of social regulation, it will be helpful to begin with a brief primer on the more evolutionarily ancient forms of these emotions. As we noted, these emotions share a common function as responses to things like lions and cliff edges. But they are also importantly different in two respects (Öhman 2008; Barlow 2001, 63; Gray and McNaughton 2000). First, their elicitation conditions differ with regard to the (un)certainty of the threat in question. Fear is a response to clear and present environmental dangers. Anxiety, by contrast, is a response to situations where the nature of the environmental threat is uncertain in the sense of involving a danger whose potential is unpredictable, uncontrollable, or otherwise open to question. Second, there are significant differences in the behaviors associated with fear and anxiety. Because fear concerns clear threats, it typically engages specific, situation-appropriate responses (e.g., particular fight/flight/freeze behaviors). Anxiety, by contrast, concerns situations involving unclear threats. So it typically leads to more general risk minimization efforts (e.g., avoidance behaviors) as well as epistemic behaviors are aimed at helping one address the uncertainty about the presumed threat (e.g., information gathering). ${ }^{4}$ In sum, while both fear and anxiety are responses to threats, they differ in that with fear, but not anxiety, the nature of the threat is clear enough to trigger specific defensive behaviors. With this background on fear and anxiety in hand, we can turn to investigate how these emotions have developed into tools of social regulation. ${ }^{5}$

\footnotetext{
${ }^{3}$ This suggests that fear and anxiety were shaped by selective processes operating at both the individual and group level (with the later likely operating on both biological and cultural features of groups). While claims about multi-level selection are controversial, they are increasingly viewed as essential and plausible elements of explanations of human cooperation (e.g., Sterelny 2012, 2013; Kitcher 2011; Richerson and Boyd 2005; Fiske 2000). I return to this in "The upshot" section.

${ }^{4}$ Work on baboons illustrates the distinct eliciting conditions and behavioral responses associated with these evolutionarily ancient forms of fear and anxiety (Cheney and Sayfarth 2007, 41-49). Spotting a lioness brings the immediate flight behavior distinctive of fear. Needing to cross a stream, by contrast, brings the risk minimization behaviors (e.g., novel stream crossing strategies) and information gathering (e.g., extended periods of observation) characteristic of anxiety. This makes sense given that fear is a response to obvious dangers (e.g., the lioness), while anxiety is a reaction to unclear ones (e.g., the crocodile that may be lurking beneath the stream's surface).

${ }^{5}$ The account of the functional differences between fear and anxiety noted in the text is supported by work showing differences between fear and anxiety at the neuroanatomical level. For instance, the evolutionary psychologist Michael Davis has demonstrated that fear and anxiety involve distinct brain structures: the central nucleus of the amygdala for fear, and the bed nucleus of the stria terminalis for anxiety (e.g., Walker et al. 2003; see also Kalin et al. 2001). For further discussion and defense of the need to see fear and anxiety as distinct emotions, see Öhman (2008); Gray and McNaughton (2000).
} 


\section{The development of fear as a tool of social regulation}

Fear is generally thought to not only have a central role in facilitating social accord, but to also have become a more sophisticated response as changes in social life demanded increasingly complex forms of social regulation. More specifically, the challenges that come with more complex social life brought selection pressures that both expanded the range of situations that provoke fear and altered the associated response behaviors. Two examples will illustrate this. ${ }^{6}$

The first example focuses on fear's role in promoting the establishment of the dominance hierarchies found in non-human primates. As the psychologist and neuroscientist Arne Öhman explains, "social fears originated in a dominancesubmissiveness system, the adaptive function of which was to promote social order by facilitating the establishment of dominance hierarchies" $(2008,711)$. For instance, the mere threat of aggression by a dominant group member can provoke fear in subordinates. In so doing, fear brings benefits to both dominants and subordinates as it helps reduce the chance of potentially violent exchanges (Öhman 1986; de Waal 1986; Boehm 2012). But how might the fear response associated with environmental threats have evolved to play this role in social regulation? At least the following three social and biological changes would have been necessary.

First, there needed to be an expansion in the range of situations that provoked fear. Individuals needed to experience fear not just in response to the presence of predators; they also needed to become fearful in the face of certain social threats (e.g., aggression and threats from other group members, instability in the group's hierarchical structures). This expansion of fear into social contexts was presumably facilitated by the fact that evolutionary pressures have made fear an extremely flexible psychological mechanism (Öhman 1986). More specifically, given the wide range of environmental threats that an individual is likely to face, fear has evolved as a general, malleable mechanism in the sense that both what an individual fears, and how it reacts, are sensitive to the particular threats that happen to occur in the individual's environment. ${ }^{7}$ But, importantly, the fear mechanism is not completely flexible. In particular, research on the elicitors of fear indicates that it brings an automatic, pre-conscious bias toward stimuli that are threat-relevant from an evolutionary perspective: snakes, spiders, and angry faces tend to bring fear, but flowers and happy faces do not (Öhman 1986; Öhman and Mineka 2001). These findings are important both because they help establish a tie between fear and threats that are significant from an evolutionary standpoint, and because they reveal that fear is biased toward not just environmental threats like snakes but also social ones like angry faces. Moreover, the automatic, pre-conscious nature of this bias and the fact that, developmentally, it is more easily acquired than is a bias toward flowers, neutral faces, and other evolutionarily-benign stimuli, proves evidence of a

\footnotetext{
${ }^{6}$ For similar accounts of the enrichment of other emotions, see Fessler (2007) (shame, pride) and Boehm (2012) (shame, conscience).

7 More precisely, fear is ballistic in the sense that tie between what elicits fear (e.g., the presence of a predator) and the subsequent behavior (e.g., flight) is very difficult to break. But it is flexible in the sense that what elicits fear and how an individual responds can vary depending on the kinds of threats that happen to be in the individual's environment.
} 
"hardwired" fear sensitivity toward these evolutionarily-significant environmental and social dangers (Öhman 1986, 2008).

Second, this sensitivity to social (not just environmental) threats needed to be accompanied by the development of new, functionally integrated cognitive capacities and motivations that enabled individuals to better recognize and respond to particular social threats (Fiske 2000). Notice, for instance, that in order for fear to function as even a simple tool of dominance-based social regulation, individuals needed to have expectations about which actions would bring aggression from others. Moreover, this (expectation of) aggression also needed to be coupled with a tendency toward greater conformity with the associated social expectations. In particular, there also needed to be changes in the motivational tendencies that fear of social threats prompts: a movement away from the fight/flight response associated with fear of predators, and toward submissive behaviors (de Waal 1986; Öhman 1986; Gibbard 1990).

Finally, the subordinate needed to develop a way to communicate to the dominant that he will not challenge the hierarchy. Here, things like the facial expression associated with fear play a crucial role. Because certain facial expressions and body postures are strongly correlated with fear (and, thus, submission), they can reliably signal to the dominant that there will be no challenge (Darwin 1873; Ekman 1992; Öhman 1986, 2008). In sum, it's in part because the fear response has become more sophisticated in these ways that it can contribute to dominance-based social regulation.

The second example concerns fear's role in the development of norm-andpunishment based social regulation. Philip Kitcher provides a nice gloss on fear's contribution:

[t]he simplest models of [the] internalization [of group norms] trade on the ability of programs of socialization to exploit human fears. ... The result is a society in which cooperation is more broadly achieved and in which costly episodes of punishment are less frequently needed. (2011, 94, emphasis added)

Fleshing this out, notice that in order for this more sophisticated, fear-based form of social regulation to be possible, at least the following pair of functionally integrated cognitive and motivational developments would have been necessary. First, there needed to be a move from the mere expectation of an aggressive response for $\Phi$-ing that is associated with dominance hierarchies, to the ability to recognize that $\Phi$-ing will violate norm $\mathrm{N}$ and so merit punishment. As Kitcher explains, recognizing that a behavior merits punishment contributes to stability by reducing the chance that allies of the punishee will come to his defense, thus escalating the conflict (89). Second, the ability to recognize that $\Phi$-ing will merit punishment needed to be accompanied by a motivational tendency toward compliance with norm N (Frank 1988; Chudek and Henrich 2013, 443).

Moreover, and as Kitcher notes, fear is likely to have played a role in these changes. Recognizing that $\Phi$-ing will violate norm $\mathrm{N}$ is initially associated with an expectation of punishment and so (anticipatory) fear. This fear in turn provides one with an incentive to comply with N. However, an emotion like fear doesn't just add 
a new incentive to the ones one already has. It also tends to bring lasting changes to the very structure of one's motivations. As a result, one complies with $\mathrm{N}$, not because one wants to avoid punishment, but because one sees $\mathrm{N}$ as independently meriting compliance. ${ }^{8}$ In this way, fear plays a crucial role in the development of a capacity for norm internalization. Moreover, notice that fear's role in norm internalization likely brought benefits to individuals and groups. Fear not only helps individuals avoid the costs of norm violation, it also allows them to signal their trustworthiness as cooperative partners-partners whose cooperation does not depend on a threat of punishment (Frank 1988). And when norms are internalized, groups are able to secure the benefits of norm adherence without the costs that come with having to (regularly) police and punish. Benefits such as these likely brought selection pressure for a more sophisticated fear mechanism —one where fear's basic sensitivity to social threats was enriched by an awareness of, and responsiveness toward, the costs of norm violation (Fiske 2000; Boehm 2012).

Stepping back, we now have two examples of how a more sophisticated capacity for fear co-evolved with increasingly complex forms of social life: the challenges and benefits that come with complex social structures likely brought selective pressure for more sophisticated forms of fear; and a more sophisticated fear mechanism brought important tools that allowed for increases in social stability and cooperation.

\section{The development of anxiety as a tool of social regulation}

While the above account of fear's development as a mechanism of both dominanceand norm-based social regulation is familiar, the picture for anxiety is less so. But given its evolutionary ties to fear, we should expect that it also became a more sophisticated regulative tool as social life grew more complex. This is what we find: the challenges associated with more complex social life brought selection pressure that both expanded the range of situations that prompt anxiety and altered the associated response behaviors. Again, two examples will illustrate.

The first example builds from research on baboons. This work illustrates how anxiety helps reduce the costs and frictions associated with dominance-based social regulation. Consider, for instance, what happens when an immigrant male joins an established baboon colony. Such an event introduces an uncertain threat. After all, the new male will need to find his place in the group's hierarchy and, in so doing, will disrupt the existing order. But who will have the misfortune of being displaced? Given the uncertainty such a situation presents, it's not surprising that male baboons respond with the epistemic and risk minimization behaviors characteristic of anxiety: with the arrival of the newcomer, the resident males "become vigilant and restless, warily tracking the new male's every move but avoiding any direct

\footnotetext{
8 The idea that emotions like anger, fear, guilt, and disgust change the structure of one's motivations is a central aspect of Robert Frank's (1988) account of emotions as tools that commit individuals to acting in ways they otherwise would not. Additional support for emotions' ability to affect one's incentive structure comes from Paul Rozin's work on disgust: coming to see a food item (e.g., a cockroach) as disgusting keeps one from eating it even after learning that it is completely safe (Rozen et al. 1986). Moreover, emotions other than fear (e.g., guilt, shame, pride) likely brought further enhancements to feardriven dimension of norm internalization (Kitcher 2011; Boehm 2012; Fessler 2007).
} 
confrontation. They seem to be assessing him from a distance, waiting for a wahoo or yawn that will reveal his fighting ability" (Cheney and Sayfarth 2007, 57). In short, the resident males' (proto) anxiety leads them to try to learn more about the newcomer's prowess (i.e., epistemic behaviors) in a non-threatening way (i.e., risk minimization). This makes sense: it's best to pick a fight only when one is likely to win; if one is likely to lose, it's better to just concede.

But here we can again ask how an emotion that originated as a response to environmental threats would have needed to evolve in order to play this role in dominance-based social regulation. At least two broad sets of changes would have been necessary. First, and like with fear, there needed to be an expansion: individuals would have needed to develop the ability to become anxious, not just in the face of uncertain environmental threats, but social ones as well. Again, this was presumably possible because evolutionary pressures shaped anxiety into an extremely flexible psychological mechanism (Öhman 2008). Moreover, like fear, anxiety is not a completely flexible mechanism in this regard. Rather, it too brings an automatic, pre-conscious bias toward stimuli that are threat-relevant from an evolutionary perspective-both environmental dangers (snakes, spiders) and social threats (angry faces). That we find this automatic bias is significant because it provides evidence (as it did for fear) of a hardwired sensitivity toward evolutionarily-significant environmental and social threats-a conclusion that gains additional support from research indicating that, developmentally, biases toward these evolutionarily-relevant threats are more easily acquired than are biases toward stimuli that are not threat-relevant from an evolutionary perspective: flowers, neutral faces, and the like (Öhman 1986, 2008; Mathews 1990).

Second, anxiety's sensitivity to social threats needed to be accompanied by new, functionally integrated cognitive capacities and motivations that allowed individuals to better recognize and respond to social uncertainty. For instance, male baboons needed to develop the ability to form expectations about social phenomena-in particular, the ability to recognize that the presence of an immigrant male will lead to a disruption of the group's hierarchy that might impact their standing (Seyfarth and Cheney 2013). Additionally, they would have needed to integrate this richer awareness with sophisticated motivational tendencies like an ability to resist engaging the newcomer until they had a sense of his fighting ability. Thus, anxiety's ability to contribute to dominance-based social regulation results not just from a new (hardwired) sensitivity to social threats, but also a capacity to enrich this sensitivity with an associated set of expectations and motivations (Fiske 2000). ${ }^{9}$

One might worry that the above discussion attributes too much cognitive sophistication to baboons. It suggests they have a very astute understanding of both where they sit in their group's hierarchy and how changes in that hierarchy can

\footnotetext{
9 As noted above, fear is better able to fulfill its role with regard to dominance-based social regulation because there's a way for the subordinate to signal submission. Moreover, this need fits well with the fact that there is a distinctive fear expression. Anxiety, by contrast, is not associated a distinctive facial expression. But this makes sense given anxiety's function: it's a mechanism geared toward information gathering and risk minimization - a function that doesn't require one to be able to signal to others that one is engaging in them.
} 
impact their standing. It might also require baboons to have the ability to attribute motivations or intentions to the immigrant male (e.g., seeing the immigrant as wanting a place in the hierarchy). While this worry is reasonable, work in primatology both indicates that baboons have these sophisticated cognitive capacities, and helps explain why having them is advantageous.

For instance, Dorothy Cheney and Robert Seyfarth have used recordings of baboon calls to investigate the baboon mind. By splicing together novel combinations of calls that violate established patterns, they can probe the boundaries of baboons' understanding of their social world (e.g., how do baboons react when they hear an aggressive vocalization from a subordinate followed by a fear bark from a dominant?). The results of their work indicate that baboons not only have a rich understanding of their hierarchies and their place in them, but also that they integrate this knowledge with their understanding of recent events. They can, for example, understand that an aggressive call is directed at them, not their neighbor, because the aggressor is related to someone with whom they recently had a dispute (Cheney and Sayfarth 2007, 98-99; Seyfarth and Cheney 2013). Moreover, experimental work indicates that baboons are capable of some (simple) forms of mental state attribution: though they fail the false-belief test, they appear to understand the motivations and intentions of others (Cheney and Sayfarth 2007, Chap. 8). ${ }^{10}$ Stepping back, recognizing that baboons (and other non-human primates) have these cognitive capacities makes sense given how complex and fluid the social dynamics of their colonies are: better knowledge of (changes in) group structure and individual intentions improves one's ability to respond appropriately to threats; this is turn contributes to the stability of the group as a whole.

The second example draws out anxiety's role in norm-and-punishment based social regulation. Consider a familiar episode of modern life. After making an inappropriate comment in an email to a group of your colleagues, you begin to feel anxious about how they will react. Given your uncertainty, you begin to check your email more frequently with hope of learning something about your colleagues' reactions. You might also send a pre-emptive apology or make some similar effort to down play the inappropriateness of your remarks. In short, your anxiety results from knowing you've done something wrong, but not knowing whether you will be reprimanded for it. And given that you're unsure about whether you will suffer repercussions, you engage in efforts to learn more about how others are reacting so you can try to minimize the force of their response.

While the anxiety provoked in a situation like this is (alas) familiar, it's important to notice that it tends to be useful for both individuals and groups. At the individual level, the anxiety that comes in the wake of a norm violation can, as this example draws out, help non-compliant individuals see that they might be punished which can, in turn, help them avoid (or reduce) the associated repercussions. But anxiety can also bring benefits to the group more generally: seeing that you recognize the inappropriateness of your

\footnotetext{
${ }^{10}$ Chimpanzees appear to have an even more robust (but still not human-like) theory of mind (Call and Tomasello 2008).
} 
comment, I may no longer feel the need to punish you. Thus, by helping to engage reparatory behaviors, anxiety can lower the costs of social regulation.

Notice however that anxiety is better able to bring these benefits to the extent that its basic sensitivity to social threats is enriched through the incorporation of more complex, functionally integrated cognitive and motivational capacities. In particular, and as revealed by the email example, anxiety is better able to contribute to social stability and accord to the extent that it enhances one's ability to (1) recognize norms and appreciate that violating them tends to bring punishment (2) appreciate that there is a gap that one can exploit between violating a norm and being punished for it, and (3) integrate this awareness with a motivation to seek out information that will allow one to identify the best ways to avoid punishment. Thus, we find a further parallel with fear: given the individual and group-level benefits that anxiety affords with regard to reducing the costs of (policing) norm violations, there was likely selection pressure for a more sophisticated anxiety mechanism-one that brings the capacity to incorporate things like (1)-(3). So, again, emotional sophistication and complex social regulation go hand in hand.

\section{The upshot}

Bringing these observations about fear and anxiety together, we can see that we have distinct but related emotions that began as defensive responses to environmental threats, and that have developed to play important roles in complex forms of social regulation. We have also gained an understanding of how this process of refinement likely happened. Looking to the role that fear and anxiety play in facilitating dominance- and norm-based social regulation has allowed us to identify specific cognitive and motivational changes that have enabled these emotions to do what they do. We saw, for instance, that fear and anxiety came to incorporate hardwired sensitivities to social (not just environmental) threats. We also saw that the benefits of these new sensitivities was further enhanced through the development of the capacity to enrich them with functionally integrated combinations of social expectations and motivations. Moreover, these more sophisticated forms of fear and anxiety brought benefits to both individuals (e.g., punishment avoidance, social awareness) and groups (e.g., improved stability, greater norm adherence). The resulting picture, then, is one on which adaptive pressures at both the individual and group levels combined to shape fear and anxiety into sophisticated tools of social regulation. ${ }^{11}$

\footnotetext{
11 A more complete defense of the evolution of fear and anxiety as tools of social regulation would involve a more fine-grained investigation of the tuning of these emotions. We should expect to see, for instance, correlations between the complexity of these emotions and the complexity of particular hominoid social structures. We should also find more refined forms of fear and anxiety as we progress through the hominin lineage. While I cannot do that here (in part because much of the needed information does not exist), the reports of de Waal (1986) and Rilling et al. (2012) provide reason for optimism (also see note 10$)$.
} 


\section{A puzzle, a proposal}

An important feature of the above account of fear's role in facilitating norm-andpunishment forms of social regulation is the claim that the punishment of some behavior $\Phi$, and the fear that it tends to provoke, reduces the tendency for group members to $\Phi$. But for this claim to be plausible, the norms must clearly articulate both what the prohibited (required) behavior $\Phi$ is, and what punishment will result from violating the norm. Were this not the case, it would be hard to understand how fear (of punishment) could regulate behavior and foster compliance with norms against $\Phi$-ing (Cushman 2013, 351-352; Chudek and Henrich 2013, 443). In what follows, I will argue that because of this need for clear norms, the types of fear and anxiety discussed so far cannot explain how groups managed to secure the stability that makes complex forms of cooperation possible. Groups also need a tool that helps them manage messy, unclear sets of norms. This tool is a distinctive, and as of yet unappreciated, form of anxiety.

To begin, our puzzle is the upshot of a mismatch between (1) what is involved in the transition from the relatively simple social structures of early hominin/human societies to the complex social life found in later large-scale civilizations, and (2) what the fear response has evolved to do. Let's start with (1). As hominin/human groups grew in size and complexity, regulating social life required larger, more complex sets of norms. But these additions and changes to a group's norms were imperfect in the sense that they generated vague, incomplete, and conflicting sets of prescriptions and prohibitions (Sterelny 2013, 2012, 8-10; Kitcher 2011, 96-98). The result was increased uncertainty about how to act and what would be punished. ${ }^{12}$ Some examples will help us understand why:

- Vague norms. Small societies are egalitarian and decisions are based on consensus (Knauft 1991; Boehm 1999; Kitcher 2011, 96). However, as groups size increases, differences in opinion multiply and securing consensus grows more difficult. Agreement can still be achieved by appealing to more general norms that gloss over points of contention. But this move to generality comes at the cost of clarity.

- Incomplete norms. With increased group size, came increased specialization (e.g., tool making, animal husbandry, farming) and the emergence of an important new class of artisans. These artisans needed time away from communal activities to develop their skills; they also need access to valuable resources (Kitcher 2011, 125-129; Sterelny 2013). This brings new problems: How much reprieve from communal duties should artisans be granted? What responsibilities do they have to make efficient use of the valuable time and materials they've been granted?

\footnotetext{
12 Work by the anthropologist Bruce Knauft (1991) indicates that increases in groups size not only brought greater normative uncertainty, but also greater violence-especially violence associated with resource access and status.
} 
- Conflicting norms. External pressures (e.g., climate change) or migration might force independent groups to combine. ${ }^{13}$ The resulting co-mingling would likely bring one group's norms into conflict with another. In such situations, whose norms should be followed? More generally, as group size and complexity increases, so do the norms. The resulting codes were unlikely to be free of conflicting prescriptions-especially to the extent that additions and revisions to the codes were ad hoc responses to problems as they arose (Kitcher 2011, 121).

Now turn to (2). As we've noted, fear can help secure social regulation only to the extent that the group's norms give clear guidance about what behaviors are prohibited (required) and so what misbehaviors will bring punishment. This means that fear-based forms of social regulation are ill-suited for dealing with the uncertainty that comes with unclear (e.g., vague, incomplete, conflicting) norms. And this leaves us with a puzzle: how did wide-spread conformity to group norms remain possible as those norms became increasingly unclear?

The answer, I propose, lies in better appreciating the role of anxiety. The basic idea is this. As norms grew in complexity, they were increasingly unable to give clear guidance about what to do. So mechanisms that could help address the resulting 'normative uncertainty' would have brought significant benefits: individuals would have a better understanding of what's prohibited; groups would have lower enforcement costs and greater stability. Moreover, since the problem here is one that concerns uncertainty, we should expect anxiety to play an important role in the solution. However, given the particular nature of the uncertainty at issuenamely, uncertainty about what to do in the face of unclear norms - the form of anxiety involved will need to be different from the anxiety about whether one will be punished that was discussed above.

This last point merits further comment. As we've seen, anxiety, as a general psychological phenomenon, is a response to uncertainty that brings a combination of risk minimization and epistemic behaviors (recall the "Evolutionary foundations: fear and anxiety" section). We've also seen that as social life became more complicated, this basic anxiety mechanism came to incorporate more sophisticated, functionally integrated cognitive capacities and motivations. The 'punishment anxiety' discussed above (in the "The development of anxiety as a tool of social regulation" section) is a case in point: it represents a form of anxiety where the (hardwired) sensitivity to social threats has been enriched by a distinctive set of cognitive capacities and motivational tendencies-enrichments that work to both help one see there's an exploitable gap between violating a norm and being punished for it, and prompt risk minimization behaviors that can reduce the chance of being reprimanded. However, in situations of the sort at issue here-situations where the underlying norms are unclear-a response of this form is of little use. Hence the need for a further enhancement of the basic anxiety mechanism—call this 'practical anxiety.'

\footnotetext{
13 See Richerson and Boyd (2013) for discussion of the significant climatic changes that occurred during the Late Pleistocene - the period from which the transition from small-scale societies to larger ones likely began.
} 
Practical anxiety is not a form of anxiety that results from uncertainty about whether one will be punished for doing wrong. Rather, it's a form of anxiety that results from uncertainty about what the norms require (forbid) you to do in the first place. As we will see, practical anxiety brings its own distinctive set of cognitive capacities and motivational tendencies: an attunement and responsiveness to normative uncertainty. As such, it both helps individuals see that there is problematic uncertainty in their group's norms, and prompts epistemic behaviors like information gathering, reflection, and deliberation that can help them work through the normative uncertainty they face. So while punishment and practical anxiety are both forms of anxiety in that they are both responses to uncertainty that bring combinations of risk minimization and epistemic behavior, they differ in that they are comprised of distinctive sensitivities and sets of functionally integrated capacities and motivations-differences that developed in response to different types of social challenges. ${ }^{14}$

The discussion that follows develops this initial account of practical anxiety and shows how it allows us to solve our puzzle. In the next section, I address an important objection to the claim that punishment and practical anxiety are distinct psychological phenomenon. I then turn to the project of showing how practical anxiety allows us to resolve our puzzle. Here's a preview. Because practical anxiety involves a distinctive type of social awareness, it helps individuals see that there is problematic uncertainty in their group's norms. Moreover, since practical anxiety also engages distinctive behaviors-especially epistemic behaviors-it helps individuals and groups better understand and so address the problems that come with having to act in the face of unclear norms. Thus, in practical anxiety we have something that can explain how conformity to group norms remained possible as those norms became increasingly unclear.

\section{Is practical anxiety a genuine psychological phenomenon?}

The distinction between punishment and practical anxiety is central to my solution to our puzzle. But it is likely to prompt skepticism. In particular, a skeptic might grant that one can identify particular patterns of behavior and label them 'punishment anxiety' and 'practical anxiety'. But she will insist that this is at best a conceptual distinction; it does not entail these are actual psychological phenomena. Thus, we need reason to believe there are forms of anxiety that map to these labels. In what follows, I show how work in psychology helps address this worry; the next section brings additional support.

\footnotetext{
${ }^{14}$ While I want to remain neutral on theories of emotion (recall footnote 2), setting that aside for the moment will help illustrate one way of fleshing out the relationship between punishment and practical anxiety sketched in the text. The earlier discussion of anxiety in non-human primates suggests that there is an anxiety affect program that can be shaped, at least to some extent, by environmental and social/cultural influences (Levenson 1999). Suppose that's correct. If so, then what makes punishment and practical anxiety both forms of anxiety is that they both engage the anxiety affect program. What makes them distinct varieties of anxiety is that they give shape to the anxiety affect program through unique, functionally integrated combinations of situational sensitivities and behavioral responses.
} 
The discussion so far suggests a parallel in the development of punishment and practical anxiety. The distinctive challenges that come with norm-and-punishment social regulation brought selection pressure for distinctive cognitive and motivational capacities-e.g., an awareness of, and responsiveness to, the exploitable gap between norm violation and punishment. The result was the enrichment of the (hardwired) sensitivity to social threats that is punishment anxiety. Similarly, the social challenges that come when groups grow in size and complexity (identified in the "A puzzle, a proposal" section) brought selection pressures for certain cognitive and motivational capacities-e.g., an awareness of normative uncertainty and a tendency to engage in epistemic behaviors. The result was practical anxiety: a further enrichment of the sensitivity to social threats. If this is correct, there should be systematic and robust patterns in both the situations that provoke anxiety and the behaviors that subsequently result-patterns that correspond to our theoretical accounts of punishment and practical anxiety. We find support for this prediction on two fronts.

First, work by the psychologist Norman Endler and colleagues regarding individual personality differences indicates that tendencies to become anxious cluster into (at least) three kinds of situations: situations where one faces a possibility of physical harm, situations where one might face socially evaluation or sanction, and ambiguous situations-situations whose novelty or difficulty make one uncertain about what to do or what will happen (Endler and Kocovski 2001). Not only do Endler's results fit nicely with our account of the distinctive dangers that different forms of anxiety evolved to track (environmental, punishment, practical), they also accord with other work on the distinctive behavioral tendencies that result from feeling anxious in these situations. Anxiety about the possibility of physical harm brings avoidance and escape behavior (Perkins and Corr 2006). Similarly, individuals anxious about how they are being evaluated by others tend to engage in efforts to make amends for possible social errors they may have made (Leary and Kowalski 1995: Chap. 5). Finally, and as we'll see more clearly below, individuals made anxious by novel or difficult decisions tend to engage in information gathering and other epistemic behaviors (MacKuen et al. 2010; Tiedens and Linton 2001). Together these findings provide empirical support not just for the distinction between punishment and practical anxiety, but for the larger theoretical account of anxiety we've been developing.

The second piece of evidence comes from work in clinical psychology on an anxiety disorder call scrupulosity. Scrupulosity is a form of obsessive-compulsive anxiety disorder that concerns moral and religious wrong-doing. More specifically, individuals suffering from scrupulosity exhibit patterns of obsessive behaviors that fall along two dimensions: (a) fears about sinning or doing wrong, and (b) fears about punishment for having sinned or done wrong (Abramowitz 2008, 156-158). Moreover, each type of obsession tends to provoke its own distinctive sets of compulsions: type-(a) obsessions tend to provoke efforts to seek information and reassurance about the correct way to act, while type-(b) obsessions typically bring efforts to avoid situations where one might do wrong, and prayer and other efforts to repent when one finds oneself having done wrong (163-168). The following excerpts from clinical case reports nicely illustrate these two forms of scrupulosity: 
Type-(a). [Ken] viewed himself as a representative of the Catholic Church, yet often doubted whether he had taken "the moral high ground" and adhered to "the requirements of Catholic law," especially in situations that presented moral ambiguity. To resolve uncertainty regarding his behavior, Ken engaged in excessive reassurance seeking by mentally reviewing his behavior, referring to the Bible, and asking others (e.g., priests, relatives) for assurances. (165)

Type-(b). Paul's obsessions included persistent unwanted sexual thoughts that occurred whenever he saw any sort of religious icon. For example, if he saw a cross, he would think "could I insert this in my rectum?" ... Paul worked hard to avoid all of the external cues. He could not attend church, see the priest or certain members of the congregation, or confront any religious icons. If these stimuli were encountered, Paul engaged in prayer rituals to atone for his sinful and blasphemous thoughts. (159)

While there is much to say about these excerpts and the phenomenon of scrupulosity in general, the key point for present purposes is that these two types of scrupulosity fit nicely with our distinction between punishment and practical anxiety. Type(a) scrupulosity gives us an actual example of the behavior distinctive of practical anxiety: Ken's anxiety results from concerns about what to do given a normatively ambiguous situation and brings epistemic behaviors - efforts to seek assurance from experts (e.g., priests)—aimed at addressing this normative uncertainty. Type(b) scrupulosity gives us an example of the behavior distinctive of punishment anxiety: Paul's anxiety results from the belief that he may face punishment for having done wrong (e.g., having blasphemous thoughts) and it brings actions (e.g., prayer) aimed at lessening the chance/severity of punishment. Thus, this clinical work provides further evidence that punishment and practical anxiety are genuine and distinct forms of anxiety. ${ }^{15}$

Stepping back, we see that work in psychology provides two lines of empirical support for the theoretical distinction between punishment and practical anxiety; and with this, skepticism about these as genuine psychological phenomena fades. ${ }^{16}$

\footnotetext{
15 Two elaborations: First, one might object that pointing to a pathological condition like scrupulosity fails to show that practical anxiety is a feature of normal individuals. This worry is misplaced. As Bunmi Olatunji and colleagues explain, "[a] substantial body of empirical research supports theoretical propositions that clinical obsessive-compulsive symptoms [including those associated with scrupulosity] have their origins in normally occurring phenomena... and that such symptoms occur on a continuum, with many individuals in the general population reporting subclinical obsessions and compulsions" (2007, 774; see also Marks and Nesse 1994). Second, while individuals suffering from scrupulosity will often exhibit both type-(a) and type-(b) behaviors, these two dimensions are disassociable (as indicated by the above case reports).

${ }^{16}$ While the argument in the text makes a strong case for practical anxiety as a distinct form of anxiety, it's worth noting that, even if this is wrong, we've still learned something important. That is, if practical anxiety turns out to just be ordinary anxiety brought on by a distinct set of cognitions (concerning, e.g., normative uncertainty), our investigation still highlights something that has gone unnoticed - namely, the important role that (practical) anxiety plays in facilitating social stability and accord.
} 


\section{Anxiety and normative uncertainty}

\section{Clarifying the puzzle}

Let's return to the puzzle from above. The central problem is that acting in the face of vague, incomplete, or conflicting norms puts one in a position where one's decision about what to do-whatever it is - can be reasonably viewed as a norm violation. This obviously raises difficulties for the individual who must decide what to do. But because normative uncertainty creates a situation where any decision can be viewed as a norm violation, it also tends to undermine social stability and cohesion at the level of the group: as it becomes less clear who needs to be punished and who can(not) be trusted, it becomes more difficult to secure stable cooperative arrangements (Sterelny 2013).

What mechanisms could help reduce normative uncertainty? Better communication and improved information channels would certainly help. But these mechanisms can only do so much: while better information may be helpful when vague norms make it unclear what acts are prohibited, it's of little assistance when the problems arise from incomplete or conflicting norms. Addressing these difficulties requires a mechanism that can spur additions to, and revisions of, the existing (problematic) norms. However, securing such norm revision is easier said than done. Since we're dealing with situations involving established norms-norms that have already been accepted by the community - making revisions is likely to require significant 'buy in' from the community (Kitcher 2011, 96-98; Gibbard 1990, Chap. 4). ${ }^{17}$ Mitigating the problems associated with normative uncertainty requires individuals/groups to have ways of both (1) recognizing that there is a problematic lack of clarity in their norms, and (2) revising those norms in a way that is interpersonally acceptable.

Enter practical anxiety. As an emotion that is felt in the face of normative uncertainty, it is well-equipped to function as the kind of social awareness mechanism needed to meet requirement (1). Moreover, practical anxiety also tends to provoke the deliberation, information gathering, and other epistemic behaviors that are important for securing the interpersonally acceptable norm revisions of requirement (2). In what follows, I flesh out these two claims. With this done, we will then be able to see how practical anxiety helps resolve our puzzle.

\section{Anxiety and social awareness}

The claim that practical anxiety functions as an important form of social awareness should not be surprising. It's just a particular instance of a generally recognized feature of emotions-namely, that emotional experiences have evaluative content: they are experiences where one grasps one's situation in a normatively loaded

\footnotetext{
17 While the need for broad community acceptance is, as we've seen ("A puzzle, a proposal" section), crucial in small-scale hunter-gatherer groups, it remains important even as group size increased and decision making became less egalitarian (Seabright 2010).
} 
way. ${ }^{18}$ In fact, noting that emotions have evaluative content helps explain why they (typically) bring beneficial motivational tendencies.

To make these points vivid, consider the glosses they suggest for some of the emotions we've been discussing-environmental fear and fear of punishment:

(1) To feel fear at the cliff edge is not just to recognize that there is a cliff before you; rather, it is to see the cliff edge as dangerous-as something to be avoided.

(2) To feel fear when considering whether to $\Phi$ in a social setting $S$, is not just to recognize that $\Phi$-ing in $S$ will bring punishment; it is to see $\Phi$-ing in $\mathrm{S}$ as inappropriate - as something to be avoided.

In each case, the emotional experience has evaluative content and motivational upshot. Applying this framework to the case of practical anxiety gives us something like the following:

(3) To feel practically anxious when considering whether to $\Phi$ in a social setting $\mathrm{S}$, is not just to recognize that the norms for $\mathrm{S}$ are unclear about the permissibility of $\Phi$-ing; it is to see this lack of clarity as problematic-as something calling for a cautious approach.

That practical anxiety raises awareness in this way is significant. Because practical anxiety brings a reflective, normatively loaded form of awareness, it can function as an alarm: it disrupts current behavior and prompts an often conscious reassessment of what one is doing (Öhman 2008, 713; Baumeister and Tice 1990, 170-172). And because practical anxiety implicates normative uncertainty as the source of the problem, it allows for a more targeted response (e.g., more focused reflection and information gathering). ${ }^{19}$

This picture of practical anxiety as a form of social awareness is further supported by empirical work indicating that anxiety functions to help individuals identify, and direct their attention toward, threatening stimuli. For instance, anxious individuals are better able to pick out angry faces (in comparison to happy or neutral ones) than are non-anxious individuals (Bradley et al. 1998; Öhman et al. 2001). Related work demonstrates that anxious individuals also look at angry faces more quickly and more often (Mogg et al. 2000). In his review of results like these, the psychologist Andrew Mathews nicely sums anxiety's role: it brings “an automatic processing bias, initiated prior to awareness, but serving to attract attention to environmental threat cues, and thus facilitating the acquisition of threatening information" (1990, 461; also see Öhman 2008).

\footnotetext{
18 Though there is much controversy over how we should understand the evaluative content of emotions (e.g., is this content the result of a judgment? does the content have propositional form?), the general claim is widely accepted (e.g., Ekman 1992; Lazarus 1991; de Sousa 1987; Nussbaum 2001; Prinz 2004).

19 Understanding how, exactly, practical anxiety implicates normative uncertainty will turn on how best to understand how emotions get their content-is it, for instance, on par with perception (e.g., de Sousa 1987, Prinz 2004) or is it the result of a more cognitively rich appraisal (e.g., Lazarus 1991, Nussbaum 2001)? Fortunately for our purposes, we can be neutral on this issue.
} 
In sum, when we combine these empirical findings with the above account of the evaluative content associated with practical anxiety, we get important support for the claim that practical anxiety can help meet the demands of requirement (1): practical anxiety is an emotion that helps individuals/groups recognize that their norms are problematically unclear. But we also get evidence for practical anxiety's ability to contribute to requirement (2): because it engages a motivational tendency to proceed cautiously, it can (as we will see) make one more attuned to the needs and concerns of others. ${ }^{20}$

\section{Anxiety and epistemic behavior}

Practical anxiety doesn't just promote social awareness and interpersonal sensitivity ("Anxiety and social awareness" section); it also tends to engage deliberation, reflection, and information gathering ("A puzzle, a proposal", "Is practical anxiety a genuine psychological phenomenon?" sections). These features suggest practical anxiety functions to prompt epistemic behaviors specifically aimed at helping one come to conclusions about what to do in the face of normative uncertainty that are responsive to the concerns of others.

This is a provocative claim. Moreover, given that "anxiety" is often thought to be an inherently destructive emotion-the anxious individual is one who is overwhelmed by his worries - it is important to see that practical anxiety really does engage epistemic behaviors that tend to have these beneficial features. We find support for this picture of practical anxiety's epistemic function in empirical work on anxiety as general psychological phenomenon. This research indicates that anxiety tends to bring distinctive forms of information gathering and processing. For instance, eliciting emotions that-like anxiety—are associated with uncertainty has been shown to bring more detail-oriented cognitive processing, and less reliance on heuristics, than does eliciting emotions associated with certainty (e.g., anger, disgust) (Tiedens and Linton 2001; also see Messer 1970). Anxiety also increases one's tendency to engage in perspective taking as one tries to better understand the nature of the situation one is in. For example, anxious individuals tend to reflect more on how others will evaluate them when they are in situations where they believe such evaluations are likely to be made (Smith et al. 1983; see also Mathews

\footnotetext{
${ }^{20}$ One might object that the discussion in the text presumes that practical anxiety always manifests in a particular way: an automatic (pre-conscious) appraisal signals that one faces normative uncertainty which then brings deliberation and information gathering. But reflection on ordinary anxious experience suggests a different picture: ruminations and worries lead one to realize that one faces unclear norms which then prompts practical anxiety and so additional rumination and deliberation. This might suggest that practical anxiety doesn't help us recognize normative uncertainty; rather, it merely helps us respond to normative uncertainty that we've identified via other means. In response, I do not deny that practical anxiety can come about through this alternative route. However, there's no reason to think this is the only_-or even the typical—way that individuals become practically anxious. First, empirical work on the appraisal processes that prompt anxiety indicates that anxious episodes are (typically) the upshot of automatic, pre-conscious mechanisms (see, e.g., the Mathew quote in the text). Second, empirical work also suggests that in cases where reflection brings anxiety, this alternative causal route is the upshot of specific (but atypical) triggers. For instance, clinical levels self-monitoring appear to engage feedback mechanisms that lead to anxiety-provoking levels of reflection (Barlow 2001).
} 
1990, 456-457; Baumeister and Tice 1990). Though focusing on details and considering the point of view of others can, in extreme cases, lead to social difficulties, in their more typical and moderate form, they tend to bring information and perspective that help one address the uncertainty one faces.

More direct support for practical anxiety's tendency to prompt beneficial epistemic behavior comes from recent work by the political scientist Michael MacKuen. This work investigates how feelings of anger and anxiety in response to a challenge to one's political policy preferences affect one's subsequent actions and attitudes (MacKuen et al. 2010). To explore this question, MacKuen and colleagues developed a web-based environment that presented subjects with an informative (but fake) news story about a school's decision to change its affirmative action policy. The story was designed to either affirm or challenge the policy preferences the subjects had reported on a pretest questionnaire. The web-based environment also provided subjects with the opportunity to explore, if they wished, additional information that would affirm, challenge, or be neutral with regard to the news story they had read. ${ }^{21}$

In the present context, MacKuen's experimental design is significant for two reasons. First, the strategy of challenging subjects' stances on affirmative action policy fits nicely with our focus on normative uncertainty. After all, affirmative action is a policy that is supported - and challenged-by independently plausible norms: equity norms say one should support affirmative action efforts, while meritocratic norms tell one not to. Thus, situations that raise questions about whether one should continue to support (oppose) affirmative action are situations that are likely to introduce the type of normative uncertainty that prompts practical anxiety. Second, by creating an environment that can induce distinct emotions (anger or anxiety) and that provides subjects with the opportunity to explore additional information sources, the experimental design provides a rather direct test of the claim that practical anxiety engages epistemic behaviors that help one work through uncertainty about what to do. The results indicate that it does. Subjects for whom the fake news story provoked anxiety displayed (in comparison with those who felt anger) a greater tendency to seek out more information about affirmative action policy, a greater interest in learning more about both sides of the issue, andperhaps most interestingly_an increased willingness to explore new solutions.

\section{Summing up}

Taken together, these different pieces of evidence-theoretical (the "A puzzle, a proposal" section), clinical (the "Is practical anxiety a genuine psychological phenomenon?" section), and experimental (the "Anxiety and social awareness", "Anxiety and epistemic behavior" sections)—nicely support the claim that practical

\footnotetext{
21 MacKuen and colleagues talk generally about 'anxiety,' not 'practical anxiety' (that's a term I've coined). But as the discussion in the text indicates, and as is readily apparent in their own presentation, they are picking out a particular variety of anxiety-one that is concerned with uncertainty about what to do rather than, say, uncertainty about how one might be evaluated (c.f., the discussion in the "Is practical anxiety a genuine psychological phenomenon?" section). For instance, there was little in the experimental design to make subjects think they were being observed or evaluated, and so little to suggest they were experiencing punishment rather than practical anxiety.
} 
anxiety functions not just as a warning device, but also as an important epistemic tool: it engages the deliberation, reflection, information gathering, and open-mindedness that can help individuals work through the problems that come with having to act on vague, incomplete, and conflicting norms, and do so in a way that makes them sensitive to the concerns of others. With the above understanding of practical anxiety's warning and epistemic dimensions in hand, we can return to our puzzle.

\section{Resolving the puzzle: anxiety and norm refinement}

When one experiences practical anxiety, one comes to see one's situation as involving problematically unclear norms; this awareness, in turn, prompts caution (the "Anxiety and social awareness" section). Moreover, given the source of one's anxiety - namely, a problematic lack of clarity in one's group's norms-one tends to engage in various epistemic behaviors. One's thinking becomes more focused on the challenge that one faces and one's perspective shifts: one is pushed to think about one's choice from the point of view of those who might call one's decision into question. This perspective taking is also accompanied by the open-minded information gathering that practical anxiety tends to provoke (the "Anxiety and epistemic behavior" section). Recognizing all this is significant. It reveals that practical anxiety can both help warn individuals (and groups) that their norms are problematically unclear, and motivate them to refine their thinking about what to do as a result. Moreover, because practical anxiety prompts (open-minded) deliberation, reflection, information gathering, and a willingness to explore new solutions, individuals who experience it are more likely to be able to justify their actions to others (Ackerman and Fishkin 2004, Chap. 3; Gibbard 1990, Chap. 4). This means that practical anxiety can help bring decisions that are (more) interpersonally acceptable. But as we've seen (the "Clarifying the puzzle" section), a mechanism of this sort is just what we need in order to explain how wide-spread norm adherence remained possible in the face of increasingly unclear norms. So understanding practical anxiety both helps us resolve our puzzle and provides us with a better understanding of how emotions help secure social stability and accord.

\section{Conclusion}

We have seen that fear and anxiety are capacities that social beings like us have developed in order to help address the problems that come with increasingly complex forms of social organization. But we have also seen that anxiety plays a distinctive and, until now, unappreciated role in helping humans manage the distinctive challenges inherent in our highly complex social structures. In particular, practical anxiety tends to be provoked when one must make a decision about how to act, but faces unclear norms about what to do. As a form of social awareness, practical anxiety helps one recognize the need to proceed cautiously in the face of these unclear norms. This awareness, in turn, prompts epistemic behaviors that help one come to conclusions about what to do that one can justify to others. This 
indicates that we should see practical anxiety not only as a form of metacognitiona form of cognition that monitors and regulates one's practical decision makingbut also as a form of metacognition that is a particularly valuable-one that helps individuals and groups come to better collective decisions about how to revise vague, incomplete, and conflicting norms.

Acknoweldgments An earlier version of this paper was presented at KU Leuven. Thanks to the participant of that conference for a helpful discussion. I have also benefited from conversations with Carl Craver, John Doris, Marta Halina, Ron Mallon, Anya Plutynski, Lizzie Schechter, and the participants in my graduate seminar on moral and philosophical psychology. Thanks as well to two anonymous referees and the Editor of the Journal for helpful suggestions.

\section{References}

Abramowitz JS (2008) Scrupulosity. In: Abramowitz J, McKay D, Taylor S (eds) Clinical handbook of obsessive-compulsive disorder and related problems. Johns Hopkins Press, Baltimore, pp 156-175 Ackerman B, Fishkin J (2004) Deliberation Day. Yale University Press, New Haven

Barlow D (2001) Anxiety and Its disorders, 2nd edn. Guilford Press, New York

Baumeister R, Tice D (1990) Anxiety and social exclusion. J Soc Clin Psychol 9:165-195

Boehm C (1999) Hierarchy in the forrest. Harvard University Press, Cambridge, MA

Boehm C (2012) Moral origins. Basic, New York

Bradley B, Mogg K, Falla S, Hamilton L (1998) Attentional bias for threatening facial expressions in anxiety: manipulation of stimulus duration. Cogn Emot 12(6):737-753

Call J, Tomasello M (2008) Does the chimpanzee have a theory of mind? 30 years later. Trends Cogn Sci 12:187-192

Cheney D, Sayfarth R (2007) Baboon metaphysics. University of Chicago Press, Chicago

Chudek Z, Henrich J (2013) Culture-gene coevolution, large-scale cooperation, and the shaping of human social psychology. In: Sterelny K, Joyce R, Calcott B, Fraser B (eds) Cooperation and its evolution. MIT Press, Cambridge, pp 425-458

Cushman F (2013) The role of learning in punishment, prosociality, and human uniqueness. In: Sterelny K, Joyce R, Calcott B, Fraser B (eds) Cooperation and its evolution. MIT Press, Cambridge, pp 333-372

Darwin C (1873) The expression of the emotions in man and animals. D. Appleton, New York

de Sousa R (1987) The rationality of emotion. MIT Press, Cambridge

de Waal F (1986) The integration of dominance and social bonding in primates. Q Rev Biol 61:459-479

Ekman P (1992) An argument for basic emotions. Cogn Emot 6:169-200

Endler N, Kocovski N (2001) State and trait anxiety revisited. J Anxiety Disord 15:231-245

Fessler D (2007) From appeasement to conformity. In: Tracey J, Robins R, Tangney J (eds) The selfconscious emotions. Gilford, New York, pp 174-193

Fiske A (2000) Complementarity theory. Personal Soc Psychol Rev 4:76-94

Frank R (1988) Passions within reason. Norton, New York

Gibbard A (1990) Wise choices, apt feelings. Harvard University Press, Cambridge

Gray J, McNaughton N (2000) The neuropsychology of anxiety. Oxford University Press, Oxford

Kalin N, Shelton S, Davidson R, Kelley A (2001) The primate amygdala mediates acute fear but not the behavioral and physiological components of anxious temperament. J Neurosci 21:2067-2074

Kitcher P (2011) The ethical project. Harvard University Press, Cambridge

Knauf B (1991) Violence and sociality in human evolution. Anthr Res 32:391-409

Lazarus R (1991) Emotion and adaptation. Oxford University Press, New York

Leary M, Kowalski L (1995) Social anxiety. Guilford Press, New York

Levenson R (1999) The intrapersonal function of emotion. Cogn Emot 13:481-504

MacKuen M et al (2010) Civil engagements. Am J Polit Sci 54:440-458

Marks I, Nesse R (1994) Fear and fitness: an evolutionary analysis of anxiety disorders. Ethol Sociobiol $15: 247-261$

Mathews A (1990) Why worry? The cognitive function of anxiety. Behav Res Ther 28:455-468 
Messer S (1970) The effect of anxiety over intellectual performance on reflection-impulsivity in children. Child Dev 41:723-735

Mogg K, Millar N, Bradley B (2000) Biases in eye movement to threatening facial expression in generalized anxiety disorder and depressive disorder. J Abnorm Psychol 109:1241-1252

Nussbaum M (2001) Upheavals of thought. Cambridge University Press, Cambridge

Öhman A (1986) Face the beast and fear the face. Psychophysiol 23:123-145

Öhman A (2008) Fear and anxiety. In: Lewis M, Haviland-Jones JM, Barrett LF (eds) Handbook of emotions. Gilford Press, New York

Öhman A, Mineka S (2001) Fears, phobias, and preparedness. Psychol Rev 108:483-522

Öhman A, Lundquist D, Esteves F (2001) The face in the crowd revisited. J Personal Soc Psychol $80: 381-396$

Olatunji B et al (2007) Scrupulosity and obsessive-compulsive symptoms. J Anxiety Disord 21:771-787

Perkins A, Corr P (2006) Reactions to threat and personality. Behav Brain Res 169:21-28

Prinz J (2004) Gut reactions. Oxford University Press, Oxford

Prinz J (2007) The emotional construction of morals. Oxford University Press, Oxford

Richerson P, Boyd R (2005) Not by genes alone. University of Chicago Press, Chicago

Richerson P, Boyd R (2013) Rethinking paleoanthropology. In: Hatfield G, Pittman H (eds) Evolution of mind, brain, and culture. University of Pennsylvania Press, Philadelphia, pp 263-302

Rilling JK, Scholz J, Preuss TM, Glasser MF, Errangi BK, Behrens TE (2012) Differences between chimpanzees and bonobos in neural systems supporting social cognition. Soc Cogn Affect Neurosci 7:369-379

Rozen Paul et al (1986) Operation of the laws of sympathetic magic in disgust and other domains. J Personal Soc Psychol 50:703-712

Seabright P (2010) The company of strangers. Princeton University Press, Princeton

Seyfarth R, Cheney D (2013) Affiliation, empathy, and the origins of theory of mind. Proc Natl Acad Sci 110:10349-10356

Smith T, Ingram R, Brehm S (1983) Social anxiety, anxious self-preoccupation, and recall of self-relevant information. J Personal Soc Psychol 44:1276-1283

Sterelny K (2012) The evolved apprentice. MIT Press, Cambridge

Sterelny K (2013) Life in interesting times. In: Sterelny K, Joyce R, Calcott B, Fraser B (eds) Cooperation and its evolution. MIT Press, Cambridge, pp 89-108

Sterelny K, Joyce R, Calcott B, Fraser B (2013) Cooperation and Its evolution. MIT Press, Cambridge

Tiedens L, Linton S (2001) Judgment under emotional certainty and uncertainty. J Personal Soc Psychol 81:973-988

Walker D, Toufexis D, Davis M (2003) Role of the bed nucleus of the stria terminalis versus the amygdala in fear, stress, and anxiety. Eur J Pharmacol 463:199-216 